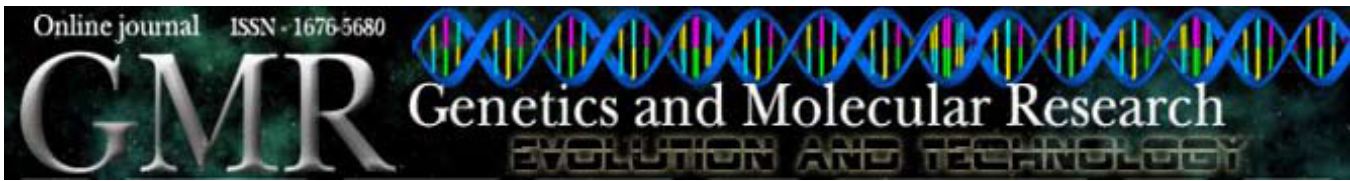

\title{
Variation characteristics of the nitrate reductase gene of key inbred maize lines and derived lines in China
}

\author{
J.J. Zhang, ${ }^{1,2}$, X.Q. Zhang', Y.H. Liu', H.M. Liu ${ }^{1}$, Y.B. Wang ${ }^{1}$, \\ M.L. Tian ${ }^{3}$ and Y.B. Huang ${ }^{1,3}$ \\ ${ }^{1}$ Maize Research Institute, Sichuan Agricultural University, Ya'an, \\ Sichuan, P.R. China \\ ${ }^{2}$ College of Life Science, Sichuan Agricultural University, Ya'an, \\ Sichuan, P.R. China \\ ${ }^{3}$ College of Agronomy, Sichuan Agriculture University, Ya'an, \\ Sichuan, P.R. China
}

Corresponding author: Y.B. Huang

E-mail: yubihuang@sina.com

Genet. Mol. Res. 9 (3): 1824-1835 (2010)

Received June 24, 2010

Accepted July 18, 2010

Published September 14, 2010

DOI 10.4238/vol9-3gmr931

\begin{abstract}
Key inbred lines have played a fundamental role in maize genetics and breeding. Research on variation characteristics of key genes from key inbred lines and from derived lines is important for early identification and evaluation of inbred maize lines. The nitrate reductase (NR) gene, which plays a central role in nitrate acquisition, was the target gene for this research. Forty-one inbred maize lines were investigated, including four key inbred lines: Huangzaosi, Mo17, Dan340, and Ye478. Through multiple sequence alignment with the NR gene from B73, used as a control, we found that: 1) the NR gene of most inbred lines from Huangzaosi and from derived lines had two insertion fragments and two replacement fragments; 2) the NR gene of most inbred lines from Mo17 and derived lines had one insertion fragment and one replacement fragment; 3) there were two common variations and eight common SNPs in the NR gene of the four key lines.
\end{abstract}


Huangzaosi and Mo17 also had three common variations compared with the other key lines. Moreover, Mo17 had some unique variations; there were no unique variations in the other key lines, even for SNPs, and 4) phylogenetic tree analysis showed that the NR gene of the derived lines from the same key line had higher sequence homology. Based on the above NR gene variation characteristics and sequence homology of key inbred lines and derived lines, a candidate inbred line can be preliminarily selected and evaluated by marker development and/or sequence alignment of the NR gene.

Key words: Maize inbred lines; Derived lines; Variation characteristics; Nitrate reductase gene

\section{INTRODUCTION}

Maize is one of the most important crops in China, and is grown on about $25.4 \mathrm{G}$ ha (Giga hectare), producing an annual yield of about $130 \mathrm{G} \mathrm{t}$ (Giga ton) and an average yield of $5.12 \mathrm{t} / \mathrm{ha}$ (Zhang, 2005). During the past 30 years, maize key inbred lines have played a very important role in maize genetics and breeding. Not only have a large number of hybrids been bred directly, but also widely spread valuable inbred lines have been derived from the key lines. In this research, the key inbred lines included were Huangzaosi, Mo17, Ye478, and Dan340. First, Huangzaosi, derived from an open-pollinated plant of Sipingtou, was the most utilized and efficient of inbred lines in maize breeding and production in China. Since it was bred in 1971, more than 42 hybrids and 70 derived lines have been bred from Huangzaosi, and the total growing area of these hybrids bred from Huangzaosi and its derived lines was more than that from any inbred line bred in China at that time (Zeng et al., 1996; Li, 1997). Meanwhile, Mo17 was the most important American line in the Lancaster group, and was introduced to China from Canada in 1971. Up to now more than 100 hybrids have been crossed with Mo17 (Xu et al., 2006), such as Zhongdan2, Nongda108 and Yandan14, and played very important roles in maize production of China. Areas growing Zhongdan2, a cross between Mo17 $\times \mathrm{Zi330}$, have been at the forefront in China for the last twenty years. In the meantime, many elite inbred lines, such as Ji846, Ji842, 4F1, and 419, derived from Mo17 have been bred in China (Lu et al., 2004), and more than 40 hybrids have been crossed with these derived lines (Xu et al., 2006). Dan340, one of the most important inbred lines of Luda Red $\mathrm{Cob}$, has been widely used because of its high resistance to disease, lodging resistance, high combining ability, and suitable fertility, so more than 30 inbred lines have been selected from Dan340. Furthermore, more than 56 hybrids were crossed with Dan340 and its derived lines (Qu et al., 2002; Ning et al., 2002). Ye478, bred from maize inbred lines 8112 and 5003, was one of the elite inbred lines of the Reid group. More than 41 hybrids were bred with Ye478 as the parent, and these hybrids have covered at least 39,570,000 hectares up to the present. In addition, more than 19 hybrids were crossed by its improved lines, which have covered at least 7,960,000 hectares (Li et al., 2005).

Why and how are a large number of widely spread valuable inbred lines selected from key lines? What is the main contribution of key inbred lines to them? How can an early prediction method or system of elite inbred lines be established? Answering these questions is very 
meaningful and difficult, so it is first necessary to understand how the key genes of important agronomical characteristics of key lines were transmitted to their offspring. In recent years, quantitative trait loci for some important maize traits were detected using simple sequence repeat (SSR) and/or amplified fragment length polymorphism. These traits include grain protein concentration (Li et al., 2009), photoperiod sensitivity (Wang et al., 2008), head smut (Chen et al., 2008), flowering time (Szalma et al., 2007), callus initiation and totipotency (Krakowsky et al., 2006), gibberella ear rot (Ali et al., 2005), plant height (Yan et al., 2003), and so on, and many key genes related to some important traits were also cloned and identified. At the same time, genetic diversity and heterotic groups of maize inbred lines were studied extensively (Taramino and Tingey, 1996; Xu et al., 2004; Menkir et al., 2005; Legesse et al., 2007). However, genetic variation of these quantitative trait loci and genes detected in the above research did not study their offspring or derived lines in depth.

Nitrate reductase (NR) catalyzes the initial step of nitrate assimilation - the reduction of nitrate to nitrite -, which is considered to be the rate-limiting step of $\mathrm{N}$ assimilation, so it plays a central role in nitrate acquisition for plants (Foyer et al., 1998; Campbell, 1999). In addition, NR is confirmed to have a major role as a source of nitric oxide, which functions in various physiological and developmental processes in plants (Stöhr and Ullrich, 1997; Desikan et al., 2002; Kolbert and Erdei, 2008). Therefore, NR is very important for growth, development and the dry matter accumulation of plants. The NR gene in maize was first cloned by Campbell (1999) (Genbank: U20450.1) and its full-length genomic DNA sequence was about $4.5 \mathrm{~kb}$ including 4 exons and 3 introns. Many studies have been devoted to the description of expression regulation and properties of NR (Huber et al., 1994; Sivasankar and Oaks, 1995; Foyer et al., 1998; Appenroth et al., 2000); however, the genetic variation in the NR gene of maize inbred lines has not been reported as yet.

In this research, 41 key maize inbred lines in China were collected and identified as experimental materials. The NR gene of 41 inbred lines was cloned and sequenced, and the NR gene variation characteristics of each key line and its derived lines were analyzed via multiple sequence alignment. The results were highly significant for establishment of an early identification system of maize key inbred lines and shortening the time period for breeding.

\section{MATERIAL AND METHODS}

\section{Plant materials}

Forty-one maize inbred lines were selected and identified by experts of the "973" Program (Major Project of Chinese National Programs for Fundamental Research and Development) team (No. 2006CB101700). In April 2008, these lines were planted at Duoying farm of the Maize Research Institute of Sichuan Agricultural University with conventional management. The inbred lines were all listed by background in Table 1, and were classified into 4 clusters determined by their pedigree information (i.e., Sipingtou, Lancaster, Reid, and Luda Red Cob). The first cluster, named Huangzaosi and its derived lines, was composed of related lines from number 101 to 130; the second cluster, named Mo17 and its derived lines, consisted of number 201 to 217, and the cluster 3 was Ye478 (number: 301); cluster 4 was Dan340 (number: 401), and their backgrounds were determined by consulting pedigree records of the maize breeding company and unit. In addition, some lines were classified by the experience of breeders as supplementary. 


\begin{tabular}{|c|c|c|c|c|c|}
\hline No. & Inbred line & Pedigree or origin & No. & Inbred line & Pedigree or origin \\
\hline 101 & Huangzaosi & Open pollinated plant of Sipingtou & 122 & Tianya4 & Wu109 $\times$ Huangzaosi \\
\hline 102 & Yuanfuhuang & Derived of Huangzaosi & 123 & $\mathrm{Ji} 444$ & A619 $\times$ Huangzaosi \\
\hline 103 & Huangzaosi-15 & Derived from Huangzaosi & 124 & DH40 & Aijin525 $\times$ Huangzaosi \\
\hline 104 & 8723 & Derived from Huangzaosi & 125 & Jing24 & Zaoshu302 $\times$ Huangzaosi \\
\hline 105 & Duo27 & Derived from Huangzaosi & 126 & Shuang 105 & Aijin525 $\times$ Weier44/Huangzaosi $\times$ santuan \\
\hline 106 & Huangyesi & (Huangzaosi $\times$ Yejihong) $\mathrm{BC} 3$ & 127 & Shuang741 & Aijin525 $\times$ Weier44/Huangzaosi $\times$ santuan \\
\hline 107 & Kanghuangsi & Derived from Huangzaosi & 128 & $\phi 61$ & Aijin $525 \times 5344 /$ santuan $\times$ Huangzaosi \\
\hline 108 & Baiyesi & Haungzaosi $\times$ Haidong013/Huangzaosi & 201 & Mo17 & $187-2 \times \mathrm{C} 103$ \\
\hline 109 & Ji35 & Jiduo142 $\times$ Huangzaosi/Huangzaosi & 202 & Qi35 & Derived from Mo17 \\
\hline 110 & Jing404 & Huangzaosi $\times$ Mobai02/Huangzaosi & 203 & 412 & Derived from Mo17 \\
\hline 111 & Wenhuang31413 & Dan340 × Huangzaosi/Huangzaosi & 204 & $4 \mathrm{~F} 1$ & Derived from Mo17 \\
\hline 112 & $\mathrm{H} 21$ & Hangzaosi $\times \mathrm{H} 84$ & 205 & Mo17-ht & A619ht $\times$ Mo17 \\
\hline 113 & Qi310 & Huangzaosi $\times$ Jin02 & 206 & Xi14 & Mo17 $\times$ Xu503 \\
\hline 114 & Jing7 & Huangzaosi $\times$ Luoxi3 & 207 & Ji846 & $\mathrm{Ji} 63 \times \mathrm{Mo} 17$ \\
\hline 115 & Chang7-2 & Huangzaosi $\times$ Wei95 & 208 & $\mathrm{Ji} 842$ & $\mathrm{Ji} 63 \times \mathrm{Mo17}$ \\
\hline 116 & $\mathrm{~K} 12$ & Huangzaosi $\times$ Weichun & 209 & Nan23232 & $\mathrm{B} 73 \times \mathrm{Mo} 17$ \\
\hline 117 & Ji853 & Huangzaosi $\times \mathrm{Zi3} 30 \mathrm{~F} 2$ & 210 & Nongda 178 & $78599 \times \mathrm{Mo} 17 / \mathrm{O} 2$ \\
\hline 118 & $\mathrm{Ji} 854$ & Huangzaosi $\times$ Zi330F2 & 211 & Huotanghuang 17 & Huotangbai42 $\times$ Hai1917/A619ht $\times$ Mo17 \\
\hline 119 & Dhuang212 & Derived from Huangzaosi & 301 & Ye478 & U8112 $\times$ Shen 5003 \\
\hline 120 & Ji856 & Huangzaosi $\times \mathrm{Zi} 330 \mathrm{~F} 2$ & 401 & Dan340 & Baigulv9 $\times$ Pod corn \\
\hline 121 & Jing7huang & Huangzaosi $\times$ Luoxi3/Huangzaosi & & & \\
\hline
\end{tabular}

\section{Extraction and detection of genomic DNA}

Total genomic DNA was isolated from the leaves of these lines at seedling stage by the CTAB (cetyl trimethylammonium bromide) method (Fulton et al., 1995). Three microliters 10 $\mathrm{mg} / \mathrm{mL}$ RNase A, an endonuclease that cleaves single-stranded RNA, was added to each DNA sample to get rid of RNA and then the DNA samples were detected with $0.7 \%$ agarose gel electrophoresis. After these samples were diluted 50 times, the absorbance (A) was measured by ultraviolet spectrophotometer (UVS). The ratio of A260/A280 was used to express the DNA purity, and the mass concentration was calculated according to A260 value.

\section{Primer design}

The existing NR gene sequence was retrieved from the National Center for Biotechnology Information (NCBI) (GenBank: U20450.1). The NR gene sequence, about $4.5 \mathrm{~kb}$ in length, was divided into 4 overlapping fragments for cloning: $1256 \mathrm{bp}$ (the first fragment, 207-1562 bp), $1528 \mathrm{bp}$ (the second fragment, 1256-2783 bp), $1498 \mathrm{bp}$ (the third fragment, 2240-3737 bp), and $797 \mathrm{bp}$ (the fourth fragment, 3591-4387 bp). Polymerase chain reaction (PCR) primers were designed using the DNAMAN software, and synthesized in the Shanghai Yingjun Biotechnology Co., Ltd. The sequences of the 4 pair primers are shown in Table 2.

\section{NR gene cloning}

PCR was performed in a $25-\mu \mathrm{L}$ reaction mixture containing $1 \mu \mathrm{L}$ genomic DNA template (40 ng/ $\mu \mathrm{L}), 2.5 \mu \mathrm{L}$ 10X PCR buffer, $1.8 \mu \mathrm{L} \mathrm{MgCl}_{2}(25 \mathrm{mM}), 2.0 \mu \mathrm{L}$ dNTP mixture (10 $\mathrm{mM}), 1.0 \mu \mathrm{L}$ each primer $(2.5 \mu \mathrm{M}), 0.3 \mu \mathrm{L}$ Taq DNA polymerase $(5 \mathrm{U} / \mu \mathrm{L}, \mathrm{TaKaRa}$, Dalian, China) and $15.4 \mu \mathrm{L} \mathrm{ddH}_{2} \mathrm{O}$. Amplification was carried out at $94^{\circ} \mathrm{C}$ for $4 \mathrm{~min}$, followed by 35 


Table 2. Primer sequences and annealing temperatures.
\begin{tabular}{lrc} 
& \\
\hline Primer sequence & Location & Annealing temperature \\
\hline 1F: 5'-ACGGCTAGGACGAGAGGAAG-3' & $207-226 \mathrm{bp}$ & $57^{\circ} \mathrm{C}$ \\
1R: 5'-CCGAGATTGGCAAGGTAGTG-3' & $1543-1562 \mathrm{bp}$ & $58^{\circ} \mathrm{C}$ \\
2F: 5'-TCACCAGTGACCAGCAACAG-3' & $1256-1275 \mathrm{bp}$ & $57^{\circ} \mathrm{C}$ \\
2R: 5'-CAGAAGCACCAGCACCAGTAC-3' & $2763-2783 \mathrm{bp}$ & \\
3F: 5'-CGGCTGAGTCGACAACTAC-3' & $2240-2729 \mathrm{bp}$ & $3715-3737 \mathrm{bp}$ \\
3R: 5'-TGGTGTTCTCGTTCCTGAAGTAC-3' & $3591-3619 \mathrm{bp}$ & $57^{\circ} \mathrm{C}$ \\
4F: 5'-CGTCGGCAAGCACATCTTC-3' & $4365-4387 \mathrm{bp}$ & \\
4R: 5'-ACAAACGCGCATATACGAGAGAG-3' & \\
\hline
\end{tabular}

Note: Based on the annealing temperature calculated by the DNAMAN software, the optimal annealing temperature for 4 different fragment primers were chosen according to the preliminary experimental results.

cycles of $94^{\circ} \mathrm{C}$ for $40 \mathrm{~s}$, annealing for 4 overlapping fragments at $57^{\circ} \mathrm{C}$ (for the $1 \mathrm{st}, 3 \mathrm{rd}, 4$ th fragments), $58^{\circ} \mathrm{C}$ (for the $2 \mathrm{nd}$ fragment) (Table 2) for $40 \mathrm{~s}$, and $72^{\circ} \mathrm{C}$ for $1.6 \mathrm{~min}$ (for the $1 \mathrm{st}$, 2nd, 3rd fragments), and $1 \mathrm{~min}$ (for the 4th fragment), followed by a final extension step at $72^{\circ} \mathrm{C}$ for $7 \mathrm{~min}$. The amplified DNA fragments were analyzed by $1.0 \%$ agarose gel electrophoresis in TAE (Tris-acetate-EDTA) buffer and visualized with ethidium bromide.

After recovered and purified from agarose gel using a DNA Gel Extraction Kit (TaKaRa), the PCR products of 4 overlapping fragments were inserted into a pMD18-T vector (TaKaRa) to transform Escherichia coli strain DH5 $\alpha$ by heat shock, and the cells were grown in Luria-Bertani (LB) medium containing ampicillin $(100 \mathrm{mg} / \mathrm{L})$ at $37^{\circ} \mathrm{C}$. And all recombinant plasmids identified by PCR were sequenced by the Shanghai Yingjun Biotechnology Co., Ltd. (ABI3730 DNA sequencing machine). To ensure the accuracy of DNA sequencing results, the target DNA fragments were sequenced by the double-sequencing method.

\section{Sequence analysis and software}

NR gene sequences of each key inbred line and its derived lines were analyzed through multiple sequence alignment with the NR gene of B73 as the control. The softwares used for sequence analysis are listed in Table 3.

\begin{tabular}{|c|c|c|}
\hline Software name & Function & Source \\
\hline DNAMAN & Primer design & LynnonBiosoft company \\
\hline DNAStar & Sequence assembly & http://www.dnastar.com/ \\
\hline ClustalX & Multiple sequence alignment & http://bips.u-strasbg.fr/fr/Documentation/ClustalX/ \\
\hline SPSS & Cluster analysis & http://www.9xz.net/soft/2200.htm \\
\hline DNAsp & SNP analysis & http://www.seekbio.com/ \\
\hline MEGA4.1b3 & Phylogenetic tree analysis & http://www.bio-soft.net/tree/MEGA.htm \\
\hline
\end{tabular}

\section{RESULTS}

\section{Detection of genomic DNA}

DNA samples abstracted from all maize inbred lines were determined with agarose gel electrophoresis (Figure 1) and UVS (data not show). The A260/A280 ratios for all samples 
were between 1.8 and 2.0. UVS and agarose gel electrophoresis showed that the DNA samples had no significant degradation and their qualities were suitable for the gene cloning and other molecular biology analysis requests.

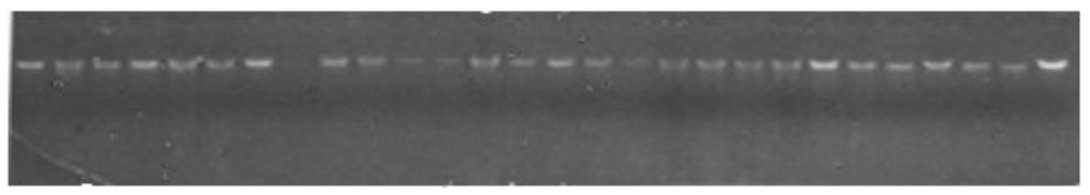

Figure 1. Leaf genomic DNA of parts of maize inbred lines purified by agarose gel electrophoresis.

\section{Cloning and identification of the NR gene}

The PCR products of 4 overlapping fragments, as shown in Figure 2, were identified by agarose gel electrophoresis. Results showed that the sizes of 4 overlapping DNA fragments were all respectively consistent with those expected. Four overlapping fragments were purified and inserted into a pMD18-T vector to transform E. coli strain DH5a, and positive clones were sequenced and analyzed.

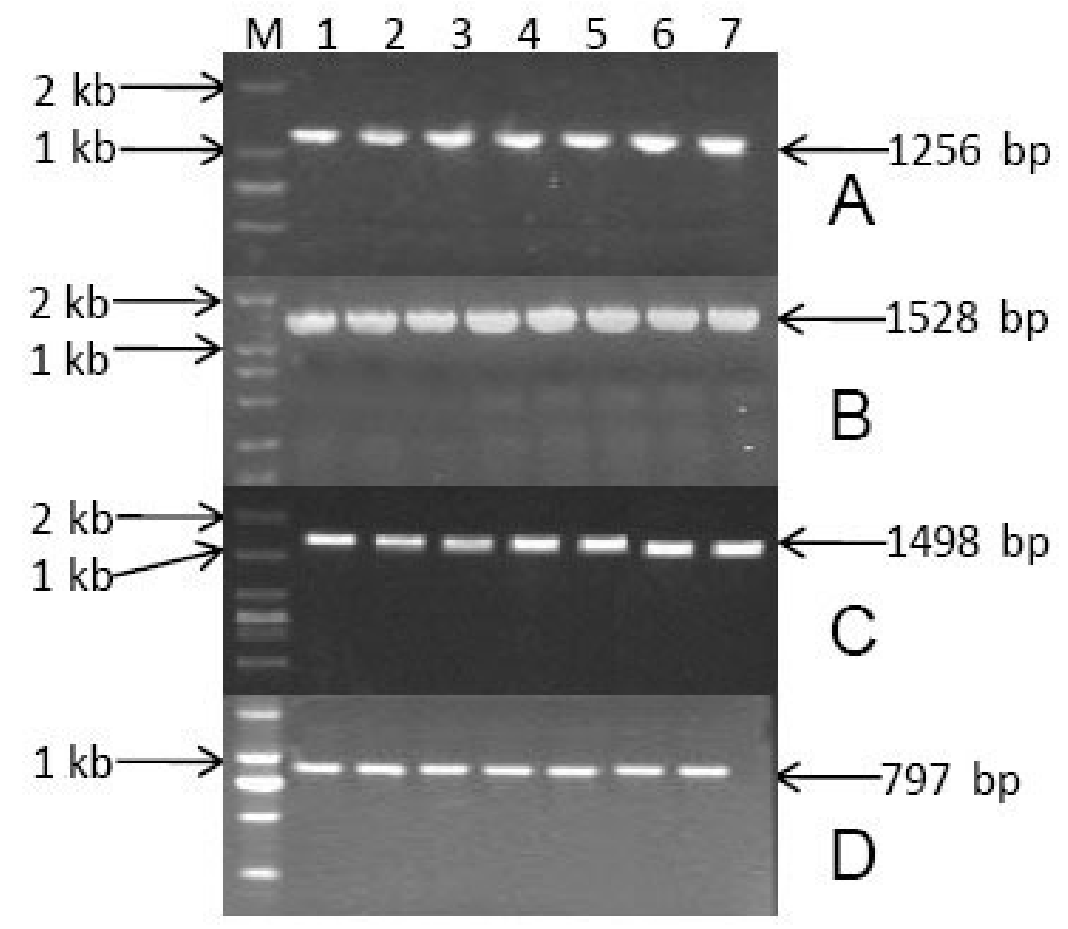

Figure 2. PCR products of 4 overlapping fragments. $M=$ DNA maker. Lanes $1-7=$ PCR products of 4 overlapping fragments. A. The first fragment. B. The second fragment. C. The third fragment. D. The fourth fragment. 


\section{NR gene sequence analysis of Huangzaosi and its derived lines}

Huangzaosi and its derived lines contained 28 inbred lines (Table 1, number 101-128). The alignment results of the NR gene showed that 11 variations were found in the NR gene of Huangzaosi and its derived lines. These variations, including single-nucleotide polymorphisms (SNPs) and a few deletions, insertions and replacement of DNA fragments, were mainly located in the 1st intron. The main variation characteristics of most inbred lines from Huangzaosi and its derived lines were analyzed. As shown in Figure 3, two insert fragments, found in the NR gene of 16 inbred lines, were $5 \mathrm{bp}$ (ATTGC) and $3 \mathrm{bp}$ (CAG) (Figure 3A). Meanwhile, two DNA fragments, ATATGCTGAAA in the 1st intron and ACG in the 4th exon, were replaced by GCTGATACGCG (Figure 3B) and CCCGGC (Figure 3C), respectively. In addition, 11 SNPs were found, including transitions and transversions, and were concentrated in the 1st intron and 4th exon (data not shown). From the above results, Huangzaosi and its derived lines were divided into two groups. The first group, including 16 inbred lines (Wenhuang31413, Yuanfuhuang, Tianyasi, Kanghuangsi, Jing404, Jing24, H21, Baiyesi, Huangyesi, Huangzaosi, Huangzaosi-15, Ji444, Ji853, Jing7, ф61, Jing7huang), had insertions and replacements of DNA fragments; however, the other group (the other lines) had only SNPs.

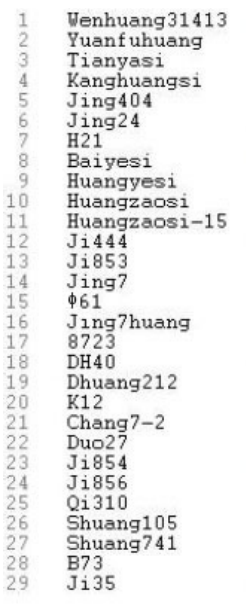

Figure 3. Main variation types of the NR gene of Huangzaosi and its derived lines. A. Two insertion DNA fragments. B. and C. Two replacement DNA fragments.

\section{NR gene sequence analysis of Mo17 and its derived lines}

Mo17 and its derived lines contained 11 inbred lines (Table 1, number 201-211). Their NR genes had about 28 variations compared with that of B73, including SNPs and insertions and replacements of DNA fragments. The common variations of Mo17 and its derived lines were mainly analyzed. The main variations were centered largely in the 1st intron and 4th exon. As shown in Figure 4, one 3-bp DNA fragment (Figure 4A) was inserted in the 4th exon, meanwhile, the "GCA" DNA fragment (Figure 4B) in the 4th exon was replaced by the "CAT" fragment. In addition, there were some common SNPs in the NR gene of Mo17 and its derived lines (Figure 4A, C, D). 

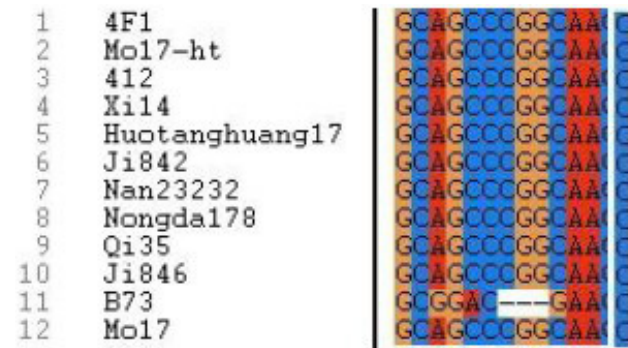

A

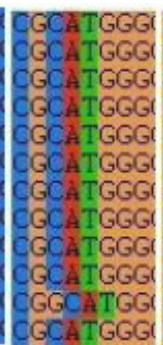

B

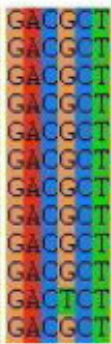

C

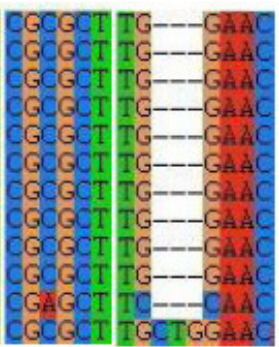

D

Figure 4. Main variation types of the NR gene of Mo17 and its derived lines. A. One insertion DNA fragment and single-nucleotide polymorphisms (SNPs). B. One replacement DNA fragment. C. and D. Some SNPs.

\section{NR gene sequence analysis of 4 key inbred lines}

Four key inbred lines contained Huangzaosi, Mo17, Dan340, and Ye478. As shown in Figure 5A, there were two common variations in the NR gene from 4 key lines by multiple sequence alignment. The first common variation was that the "GCAT" in the 4th exon was replaced by "CATG"; the second common variation was that the "GGC" fragment was inserted in the 4th exon. In addition, the NR gene from the 4 key lines had 8 common SNPs compared with that of B73. The NR gene from Huangzaosi and Mo17 also had three common variations in the 1st intron compared with that from the other key lines (Figure 5B). Two DNA insertion fragments, "CATTG" and "CTG", were found, and one DNA fragment "ATATGCTGAAA" was replaced by "GCTGATACGCG".

$\begin{array}{ll}1 & \text { Ye478 } \\ 2 & \text { Dan340 } \\ 3 & \text { B73 } \\ 4 & \text { Huangzaosi } \\ 5 & \text { Mo17 } \\ 1 & \text { Ye478 } \\ 2 & \text { Dan340 } \\ 3 & \text { B73 } \\ 4 & \text { Huangzaosi } \\ 5 & \text { Mo17 } \\ 1 & \text { Ye478 } \\ 2 & \text { Dan340 } \\ 3 & \text { B73 } \\ 4 & \text { Huangzaosi } \\ 5 & \text { Mo17 }\end{array}$

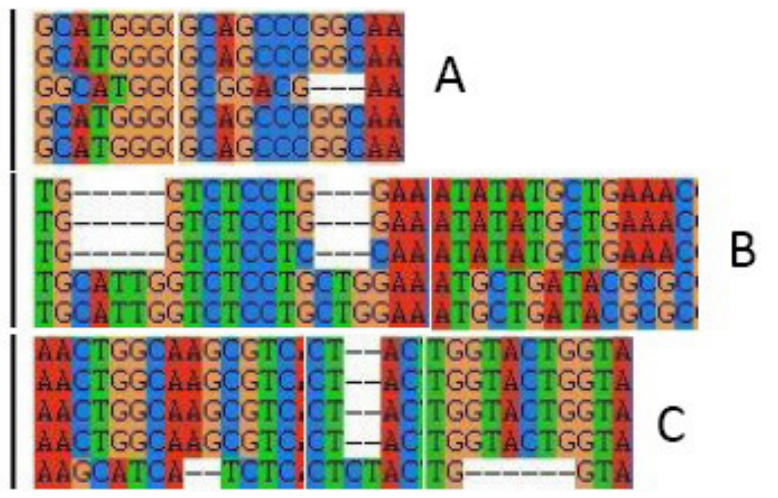

Figure 5. Variation types of the NR gene of 4 key lines with B73 as control. A. Two common variations in the NR gene from 4 key lines. B. Three common variations of the NR gene from Huangzaosi and Mo17. C. Unique variations of the NR gene from Mo17.

The NR gene from Mo17 had many unique variations including insertions, deletions and replacements of DNA fragments and some SNPs (Figure 5C), most of which were located in 2600-2900 bp. Two deletion fragments, "AG" and "GTACTG", and one insertion frag- 
ment, "CT", were found, and they were located in between the 2nd and 3rd intron. In addition, "CTGG" in the 2nd intron was replaced by the "GCAT" fragment, while for the other key lines no unique variations were found, even for SNPs.

\section{Phylogenetic tree analysis of the NR gene}

The results of the phylogenetic tree analysis based on NR gene sequences indicated that 41 maize inbred lines were divided into 3 main groups (Figure 6). The lines, except the Mo17 line (marked with triangles), were clustered into class I, and were from Huangzaosiderived lines. The lines (marked with squares) clustered into cluster class II, were all from Huangzaosi and its derived lines. The other lines, except Ye478 and Dan340 (marked with circles), were clustered into class III, and were Mo17-derived lines.

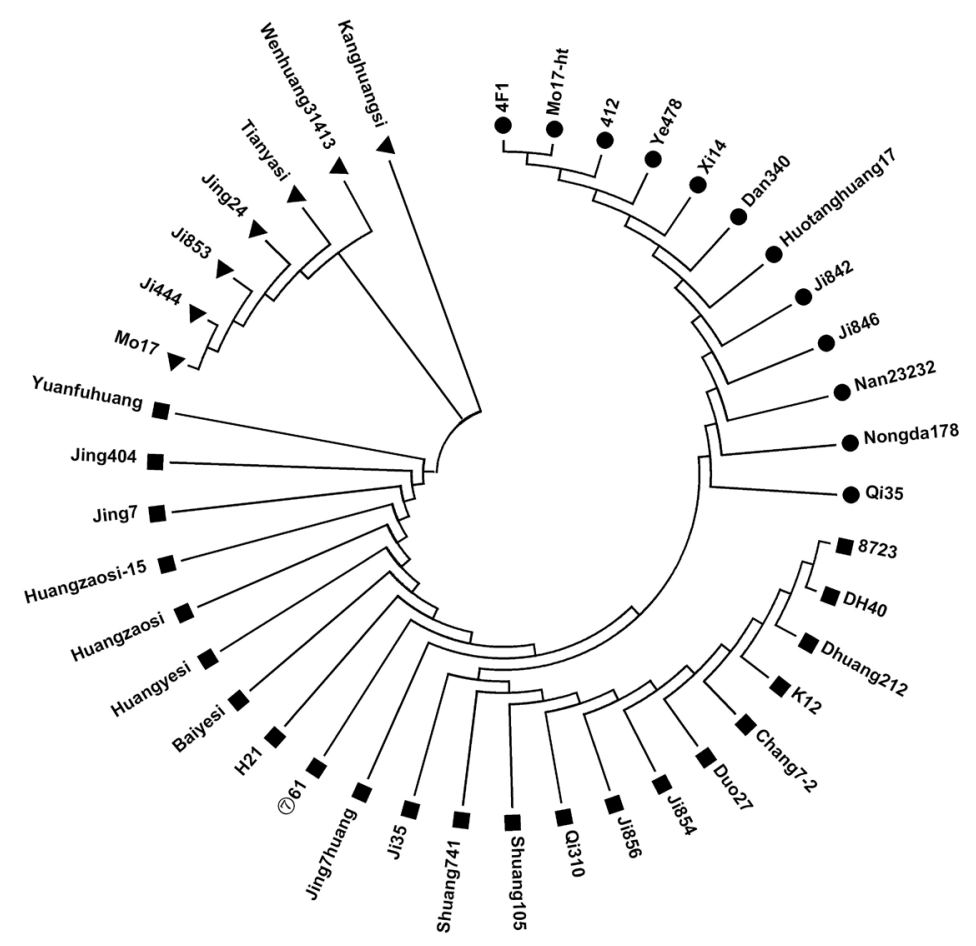

Figure 6. Phylogenetic tree of the NR gene of maize inbred lines. The tree was generated using the neighborjoining method with bootstrap support by 1000 replicates. Triangles represent the lines that were clustered into class I. Squares represent the lines that were clustered into class II. Circles represent the lines that were clustered into class III.

\section{DISCUSSION}

Key inbred lines have bred a lot of widely spread hybrid and inbred lines, and possess both excellent characteristics and high combining ability (Zhuang, 2003). During the past 30 
years in China, key inbred line has played a crucial role in maize variety improvement. Deep understanding of the formation mechanism of key inbred lines is necessary for future maize breeding. Chinese maize inbred lines were divided into 4 heterotic groups (i.e., Sipingtou, Luda Red Cob, Ried, and Lancaster) (Wang et al., 1997; Li et al., 2003). However, maize inbred lines in China were divided into 6 clusters with SSR markers by Li et al. (2003) and Zhang et al. (2007), which corresponded to the heterotic groups determined by their pedigree information and breeders' experiences. In this paper, the inbred lines in our research were included in 4 main heterotic groups (i.e., Sipingtou, Luda Red, Cob, Reid, and Lancaster) according to their pedigree information.

Each inbred line has its own characteristics, which could be inherited stably by its offspring. Therefore, it is very essential to detect the characteristics at the gene level for early detection and selection of inbred lines. Chuanchai et al. (2010) reported that parental components could be chosen in early-generation hybrid testing using the SSR technique, and hybrid performance could be predicted by using field data of related genotypes and SSR molecular markers (Schrag et al., 2010). Lu et al. (2009) screened 770 maize inbred lines with 1034 SNPs markers and identified 449 high-quality markers with no germplasm-specific biasing effects. In addition, marker-assisted selection presents the potential to improve the efficiency of plant breeding by allowing for the transfer of these specific genomic regions of interest and accelerating the recovery of the elite parent background (Stevens, 2008). However, research on variation characteristics of key genes involved in these characteristics of key lines has not been reported for key lines and derived lines.

The NR gene, playing a central role in nitrate acquisition, is very important for growth, development and the dry matter accumulation of plants (Foyer et al., 1998; Campbell, 1999). However, the research on NR is mainly limited to expression regulation and properties of NR (Huber et al., 1994; Sivasankar and Oaks 1995; Foyer et al., 1998; Appenroth et al., 2000), and the genetics and variations of the NR gene in maize inbred lines have not been reported as yet. In this study, whole sequences of the NR gene from 41 maize inbred lines were mainly analyzed by multiple sequence alignment, and the unique variation characteristics in the NR gene of each key line and its derived lines were found. In addition, the NR gene of Mol7 and its derived lines had more variations than that of Huangzaosi and its derived lines with the NR gene of B73 as the control. However, how these variations affect the expression and function of NR in each key line and its derived lines still needs to be further explored. Phylogenetic tree analysis showed that key inbred lines Dan340 and Ye478 had higher sequence homology with Mo17 and its derived lines than Huangzaosi and its derived lines, which was inconsistent with their pedigree information. Although we knew that a single gene could not really reflect their genetic relationship because a single gene cannot represent the whole genome, the overall tendency was that the derived lines from the same key inbred line had a closer relationship. According to NR gene variation characteristics and sequence homology of each key inbred line and its derived lines, a candidate inbred line can be preliminarily indicated and evaluated by marker development and/or sequence alignment of the NR gene, which would provide an idea or method for establishment of early identification systems for maize inbred lines.

\section{ACKNOWLEDGMENTS}

The authors thank Prof. Li Yu (Institute of Crop Science, Chinese Academy of Ag- 
ricultural Sciences) for providing the maize materials and good advice. Research supported by a grant from Major Project of Chinese National Programs for Fundamental Research and Development (973 Program) (\#2006CB101700).

\section{REFERENCES}

Ali ML, Taylor JH, Jie L, Sun G, et al. (2005). Molecular mapping of QTLs for resistance to Gibberella ear rot, in corn, caused by Fusarium graminearum. Genome 48: 521-533.

Appenroth K, Meco R, Jourdan VV and Lillo C (2000). Phytochrome and post-translational regulation of nitrate reductase in higher plants. Plant Sci. 159: 51-56.

Campbell WH (1999). Nitrate reductase structure, function and regulation: bridging the gap between biochemistry and physiology. Annu. Ver. Plant Physiol. Plant. Mol. Biol. 50: 277-303.

Chen Y, Chao Q, Tan G, Zhao J, et al. (2008). Identification and fine-mapping of a major QTL conferring resistance against head smut in maize. Theor. Appl. Genet. 117: 1241-1252.

Chuanchai P, Tan XI, Silapapun A and Suthipong P (2010). Early hybrid testing in tropical maize: are molecular markers useful for selecting the parental component? Kasetsart J. Nat. Sci. 44: 70-78.

Desikan R, Griffiths R, Hancock J and Neill S (2002). A new role for an old enzyme: nitrate reductase-mediated nitric oxide generation is required for abscisic acid-induced stomatal closure in Arabidopsis thaliana. Proc. Natl. Acad. Sci. U.S. A. 99: 16314-16318.

Foyer CH, Valadier MH, Migge A and Becker TW (1998). Drought-induced effects on nitrate reductase activity and mRNA and on the coordination of nitrogen and carbon metabolism in maize leaves. Plant Physiol. 117: 283-292.

Fulton TM, Chunwongse J and Tanksley SD (1995). Microprep protocol for extraction of DNA from tomato and other herbaceous plants. Plant Mol. Biol. Rep. 13: 207-209.

Huber JL, Redinbaugh MG, Huber SC and Campbell WH (1994). Regulation of maize leaf nitrate reductase activity involves both gene expression and protein phosphorylation. Plant Physiol. 106: 1667-1674.

Kolbert Z and Erdei L (2008). Involvement of nitrate reductase in auxin-induced NO synthesis. Plant Signal Behav. 3: 972-973.

Krakowsky MD, Lee M, Garay L, Woodman-Clikeman W, et al. (2006). Quantitative trait loci for callus initiation and totipotency in maize (Zea mays L.). Theor. Appl. Genet. 113: 821-830.

Legesse BW, Myburg AA, Pixley KV and Botha AM (2007). Genetic diversity of African maize inbred lines revealed by SSR markers. Hereditas 144: 10-17.

Li SS (1997). Selection and application of maize inbred line huangzaosi. Beijing Agric. Sci. 15: 19-21.

Li DH, Mao LH, Yang JS and Liu JG (2005). Breeding process and utilization of excellent maize inbred line 478. $J$. Laiyang Agric. Coll. 22: 159-164.

Li XH, Yuan LX, Li XH and Zhang SH (2003). Heterotic grouping of 70 maize inbred lines by SSR markers. Sci. Agric. Sinica 36: 622-627.

Li Y, Wang Y, Wei M and Li X (2009). QTL identification of grain protein concentration and its genetic correlation with starch concentration and grain weight using two populations in maize (Zea mays L.). J. Genet. 88: 61-66.

Lu BL, Zhao WY and Liu RZ (2004). The influence and contribution of the hybrids crossed by Mo17 deriving self inbred lines to the production of China. J. Maize Sci. 12: 127-128.

Lu Y, Yan J, Guimaraes CT, Taba S, et al. (2009). Molecular characterization of global maize breeding germplasm based on genome-wide single nucleotide polymorphisms. Theor. Appl. Genet. 120: 93-115.

Menkir A, Kling JG, Badu-Apraku B and Ingelbrecht I (2005). Molecular marker-based genetic diversity assessment of striga-resistant maize inbred lines. Theor. Appl. Genet. 110: 1145-1153.

Ning JL, Gao HM, Qu G and Yu B (2002). Utilization of inbred lines of Ludahonggu group in corn breeding and production in China. Rain Fed. Crops 22: 63-65.

Qu G, Xu WW, Chen DY and Li FZ (2002). Selection and application of superior maize inbred line Dan340. J. Maize Sci. 10: 30-33.

Schrag TA, Mohring J, Melchinger AE, Kusterer B, et al. (2010). Prediction of hybrid performance in maize using molecular markers and joint analyses of hybrids and parental inbreds. Theor. Appl. Genet. 120: 451-461.

Sivasankar S and Oaks A (1995). Regulation of nitrate reductase during early seedling growth (a role for asparagine and glutamine). Plant Physiol. 107: 1225-1231.

Stevens R (2008). Prospects for using marker-assisted breeding to improve maize production in Africa. J. Sci. Food Agric. 88: 745-755. 
Stöhr C and Ullrich WR (1997). A succinate-oxidising nitrate reductase is located at the plasma membrane of plant roots. Planta 203: 129-132.

Szalma SJ, Hostert BM, Ledeaux JR, Stuber CW, et al. (2007). QTL mapping with near-isogenic lines in maize. Theor. Appl. Genet. 114: 1211-1228.

Taramino G and Tingey S (1996). Simple sequence repeats for germplasm analysis and mapping in maize. Genome 39: 277-287.

Wang CL, Cheng FF, Sun ZH, Tang JH, et al. (2008). Genetic analysis of photoperiod sensitivity in a tropical by temperate maize recombinant inbred population using molecular markers. Theor. Appl. Genet. 117: 1129-1139.

Wang YB, Wang ZH, Wang YP and Zhang X (1997). The analysis of heterotic group and improve of Chinese maize germplasm. Acta Agric. Boreali-Sinica 13: 74-80.

$\mathrm{Xu}$ SX, Liu J and Liu GS (2004). The use of SSRs for predicting the hybrid yield and yield heterosis in 15 key inbred lines of Chinese maize. Hereditas 141: 207-215.

Xu YR, Liu XE, Sun FM and Jiao RH (2006). The application of Mo17 and derived in Chinese. J. Jilin Agric. Sci. 31: 26-28.

Yan JB, Tang H, Huang YQ, Shi YG, et al. (2003). Genomic analysis of plant height in maize through molecular marker. Sci. Agric. Sinica 10: 1069-1075.

Zeng SX, Ren R and Liu XZ (1996). The important position of huangzaosi in maize breeding and production in China. $J$. Maize Sci. 4: 1-6.

Zhang SH (2005). Maize Production and Research in China: Advancement and Challenges, p. 3. In: Proceedings of the Ninth Asia Regional Maize Workshop, September 5-9, Beijing.

Zhang JH, Zhang JY, Yang XH, Jin H, et al. (2007). A study on genetic relationship of main maize inbred lines in Yunnan by SSR markers. J. Maize Sci. 15: 30-35.

Zhuang QS (2003). Chinese Wheat Improvement and Pedigree Analysis. Agricultural Publishing House, Beijing. 